\title{
PROFIL DAYA TAHAN KARDIORESPIRASI VASCULAR ATLET PUTRI FINSWIMMING KU C DAN D DRAGON WIRA YUDHA KOTA KEDIRI TAHUN 2019
}

\author{
Imam Sugeng ${ }^{1}$, Nanda Iswahyudi ${ }^{2}$ \\ Prodi Pendidikan Jasmani, Kesehatan dan Rekreasi, Universitas Kahuripan Kediri \\ 1imamsugeng@kahuripan.ac.id, 르andaiswahyudi@kahuripan.ac.id
}

\begin{abstract}
Abstrak
Tujuan penelitian ini adalah Untuk mengetahui profil daya tahan kardiorespirasi vascular atlet putri KU C-D finswimming pila guburnur jawa timur 2019. Metode penelitian menggunakan metode survei dengan menggunakan Tes Lari 1000 meter (TKJI). Populasinya adalah seluruh atlet putri finsswimming $\mathrm{Ku} \mathrm{C}$ dan $\mathrm{D}$ yang mengikuti kejunas piala gubernur jawatimur 2019 yang berjumlah 14 atlet penyumbang mendali.. Teknik sampling yang digunakan adalah total sampling dengan jumlah 14 atlet putri. Teknik analisis data dalam penelitian ini adalah menggunakan statistik deskriptif. Statistik deskriptif adalah statistik yang digunakan untuk menganalisis data dengan cara mendeskriptifkan atau menggambarkan data yang telah terkumpul. Berdasarkan hasil penelitian terhadap 14 atlet putri finsswimming $\mathrm{Ku} C$ dan D yang mengikuti kejunas piala gubernur jawatimur 2019 yang melakukan Tes daya tahan kardiorespirasi vascular ini diukur menggunakan lari 1000 meter. Hasil data yang diperoleh akan dimasukkan ke dalam nilai norma Lari 1000 m kebugaran jasmanai yang kemudian dijadikan patokan untuk mengetahui daya usia 13-15 tahun. Hasil penelitian menunjukkan bahwa; Tingkat daya tahan kardiorespirasi vascular seluruh atlet putri finsswimming Ku C dan D yang mengikuti kejunas piala gubernur jawatimur 2019 diketahui terdapat 5 atlet memiliki tingkat daya tahan kardiorespirasi vascular kategori sangat dengan persentase 35\%, dan terdapat 9 atlet memiliki tingkat daya tahan kardiorespirasi vascular kategori baik dengan persentase $65 \%$, dan tidak atlet yang memiliki tingkat kesegaran jasmani dalam kategori sedang, kurang serta kurang sekali. Berdasarkan hasil penelitian dan pembahasannya, maka dapat diambil suatu simpulan sebagai berikut: untuk mendapatkan mendali emas dalam setiap kejuaraan maka atltet diharuskan harus memiliki daya tahan yang sangat baik.
\end{abstract}

Kata kunci: Profil, Daya Tahan, Atlet Finswimming.

\section{PENDAHULUAN}

Kota kediri mengikuti kejuaran finsswimming piala Gubernur Jawa
Timur pada tanggal 16-18 November 2019 di Kota Surabaya, yang bertempat di kolam Kertajaya Surabaya. Kota 
Kediri menurunkan atlet 40 atlet yang dibagi 18 putra dan 32 putri. Hasil dari kejuaraan tersebut memper oleh 1 emas, 7 perak dan 17 perunggu. Hasil tersebut paling banyak di subangkan oleh atlet di KU D dan C yang berjumlah atlet 18 atlet dengan mendapatkan mendali 14 medali dari Klub Dragon Wirayudha. Dragon Wira Yudha adalah klub yang mulai berkembang dan fokus di cabor aquatik yaitu selam (finnsswimming) yang, yang bermakas di bawah lereng gunung klotok di bawah naungan markas Brigrif Wira Yudha.

Finsswimming atau selam adalah olahraga yang mulai digemari oleh para atlet muda di kota kediri. Hal tersebut dibuktikan diajang prorprov, Kota Kediri mendapatkan 2 mendali emas dan 2 perak diajang bergengsi 4 tahunan tersebut. Finsswimming adalah jenis perlombaan yang menggunakan alat berupa monofin atau bifin. Pada dasarnya olahraga selam itu tidak jauh berbeda dengan olah raga renang, dan kedengarannya cabang olahraga selam ini masih asing bagi kebanyakan orang. Olahraga selam ini merupakan perkembangan dari olahraga renang, pada dasarnya atlet menggunakan peralatan seperti monofin atau bifin, dan snorkel.

Cabang olah raga selam atau finsswimming atlet harus di dukung dengan kondisi fisik yang baik dalam melakukan aktivitas olahraga sehingga mampu melakukan aktivitas olahraga yang dilakukannya tanpa mengalami kelelahan yang berlebihan, sebaliknya apabila seseorang atlet memiliki kondisi fisik yang kurang baik apalagi buruk maka seseorang akan kesulitan dalam melakukan aktivitas olahraga tersebut sehingga menyebabkan kelelahan yang berlebihan.

Menurut Syafruddin dalam Pitdin Ahmadi (2014:3) "kondisi fisik umum adalah merupakan kemampuan dasar untuk mengembangkan kemampuan prestasi tubuh yang terdiri dari komponen kekuatan, kecepatan, daya tahan dan kelentukan. Misalkan di olahraga selam pada saat melakukan sprint 50 meter membutuhkan kecepatan, sedangkan pada saat melakukan nomer 200-400 meter membutukan kekekuatan dan daya tahan yang bagus dikarenakan jarak yang ditempuh cukup panjang. Berdasarkan paparan diatas dapat disimpulkan bahwa daya tahan sangatlah berpengaruh sangat penting bagi seorang atlet, di mana atlet yang memiliki daya tahan yang bagus pasti lebih siap melakukan suatu pertandingan, apabila atlet memiliki daya tahan yang kurang bagus cenderung akan lebih cepat lelah dalam melakukan sebuah latihan maupun didalam pertandingan.

Daya tahan (endurance) memiliki peranan yang sangat penting bagi atlet di cabang olahraga selam 
(finsswimming), jika seorang atlet ingin mendapatkan daya tahan tubuh yang baik harus melalui proses latihan. Di mana tujuan latihan adalah membantu, meningkatkan keterampilan dan potensi atlet semaksimal mungkin. Pengukuran daya tahan dapat dilakukan dengan cara mengukur (VO2max). VO2 max adalah jumlah maksimal oksigen yang dapat dikonsumsi selama aktivitas berlangsung sampai akhirnya terjadi kelelahan. Menurut Guyton, dalam Yan Syantica (2013:3) "VO2Max ini disebut tenaga aerobik maksimal yang menunjang seseorang dalam melakukan aktivitas jasmaninya". Untuk mengetahui baik buruknya VO2max dapat di lakukan pengukuran sebagai analisis suatu program latihan bagi atlet yang sedang berkembang, agar efektif sebaiknya latihan endurace meliputi durasi, frekuensi, dan itensitas latihan tertentu.

Anak-anak yang terlatih olahraga secara teratur dan terus menerus, terutama olahraga aerobik akan berpengaruh dalam meningkatkan kemampuan transport oksigen dan akan meningkatkan VO2Max 10\% sampai 20\%. Bentuk olahraga yang dapat meningkatkan kapasitas transport oksigen, antara lain: lari, renang, bersepeda, sepakbola termasuk bulutangkis dan sejenisnya (Sharkey \& Brian J, 2003:68). Dengan demikian paparan di atas dapat disimpulkan VO2max memeliki peranan penting untuk menunjang atlet dalam berprestasi.

Berdasarkan wawancara dan ovservasi pada kejuaran finswimming piala gubernur tahun 2019 dengan coach Yanuar Rizki menyatakan bahwa Klub Dragon Wira Yudha adalah klub yang baru berdiri sekitar 4 tahun yang lalu, akan tetapi perkembangan klub tersebut begitu pesat di event kejuaraan nasional ini dan rata rata anak-anak mendapatkan mendali di nomer-nomer sprinter yaitu 50 dan 100 meter, akan tetapi di nomer 200 dan 400 meter anak-anak masih belum maksimal dikarenakan selama latihan anak-anak hanya fokus di teknik saja dan belum pernah dilakukan tes pengukuran daya tahan atlet ( VO2max) selama ini.

Berdasarkan uraian di atas penulis tertarik untuk melakukan penelitian yang berjudul "Profil Kemampuan Daya Tahan kardiorespirasi vascular Atlet yang mengikuti kejuaraan finswimming piala gubernur Jawa Timur KU C dan D putri".

\section{KAJIAN TEORI}

Kondisi fisik memegang peranan yang sangat penting untuk menunjang prestasi seorang atlet, tanpa kondisi fisik yang bagus dan prima mustahil atlet akan mendapatkan prestasi yang bagus 
pula. Kondisi fisik yang baik mempunyai keuntungan, yaitu atlet mudah mempelajari keterampilan yang sulit, tidak mudah lelah mengikuti latihan, pertanding dan dapat menyelesaikan program latihan tanpa ada kekelahan yang berarti. Kondisi fisik memiliki dapat di definisikan yaitu satu kesatuan yang utuk tidak dapat di pisahkan dari komponen komponen untuk perbaikan atau peningkatan.

Pendapat tersebut di kuatkan oleh Menurut Nuril Ahmadi (2007:65) kondisi fisik adalah suatu kesatuan utuh dari komponen-komponen yang tidak dapat dipisahkan begitu saja, baik peningkatan maupun pemeliharaanya, Sejalan dengan pendapat Sajoto (1988:57), kondisi fisik adalah salah satu prasarat yang sangat diperlukan dalam usaha peningkatan prestasi seorang atlet, bahkan sebagai landasan titik tolak suatu awalan olahraga prestasi. Dapat disimpulkan bahwa kondisi fisik yaitu suatu usaha yang dikembangkan untuk meningkatkan komponen-komponen tersebut. Selain kondisi fisik daya tahan juga memiliki peranan penting bagi atlet. Daya tahan adalah salah satu komponen biomotor utama/dasar dalam setiap cabang olahraga. Komponen biomotor daya tahan secara umumnya dapat digunakan sebagai tolok ukur mengetahui tingkat kebugaran jasmani (physical fitnes) olahragawan.
Sukadiyanto

(2005:57)

menjelaskan pengertian daya tahan ditinjau dari kerja otot adalah kemampuan kerja otot atau sekelompok dalam jangka waktu tertentu, sedangkan pengertian daya tahan dari sistem energi adalah kemampuan kerja organ-organ tubuh dalam jangka waktu tertentu. Berdasarkan paparan diatas daya tahan dapat disimpulkan bahwa suatu komponen biomotor dasar dan utama untuk melawan kelelahan selama berlangsungnya aktivitas atau kerja.

VO2max atau tenaga aerobik maksimal atau disebut juga penggunaan oksigen maksimal adalah tempo tercepat dimana seseorang dapat menggunakan oksigen selama berolah raga (Brooks dan Fahey, 1985:78). Fungsi kardiovaskuler menentukan besarnya VO2Max, yang selanjutnya menentukan kapasitas kerja fisik atau kebugaran. Salah satu cara penting untuk menentukan kebugaran kardiovaskuler adalah mengukur besarnya VO2Max. Oleh karena itu, VO2Max atau kapasitas aerob bukan hanya sekedar parameter metabolisme melainkan merupakan ukuran handal dalam kebugaran jasmani (Brooks dan Fahey, 1985: 81). Dadapun faktor yang mempengaruhi nilai Vo2 max antara lain 1. Usia, 2. Jenis kelamin, 3. Suhu, 4. Keadaan latihan. 


\section{METODE PENELITIAN}

Metode

penelitian menggunakan metode survei. Survei adalah mencari informasi tentang apa yang sedang diamati atau diteliti. Hal ini dapat dijelaskan bahwa tujuan penelitian ini adalah mengumpulkan data dalam bentuk tes untuk mengetahui daya tahan umum pada atlet finswimming piala Gubernur Jawa Timur KU C dan D putri kota kediri.

Pendekatan yang digunakan dalam penelitian ini adalah pendekatan kuantitatif. Pendekatan kuantitatif adalah pendekatan yang menggunakan angka dan statistika sebagai alat untuk pengolahan data dan dasar pengambilan keputusan (Arikunto, 2014).

Populasi menurut Arikunto (2010:108) adalah keseluruhan subjek penelitian, sedang menurut Sukardi (2004:53) populasi pada prinsipnya adalah semua anggota kelompok manusia, binatang, peristiwa atau benda yang tinggal bersama dalam satu tempat dan secara terencana menjadi target kesimpulan dari hasil akhir suatu penelitian. Adapun Populasi dalam penelitian ini adalah atlet putri finsswimming $\mathrm{Ku} C$ dan $\mathrm{D}$ yang mengikuti kejunas piala Gubernur Jawa Timur 2019 yang berjumlah 14 atlet penyumbang mendali.

Atlet melakukan tes daya tahan kardiorespirasi vascular yang menggunakan parameter tes kebugaran jasmani yaitu lari 1000. Tes digunakan untuk memperoleh data yang akan dimasukan di norma lari 1000 meter. Berikut ini norma lari 1000 meter untuk mengetahui daya tahan:

Data yang diperoleh dari tiaptiap item tes merupakan data yang dicapai atlet. Selanjutnya hasil yang sudah dicapai atlet dari tiap-tiap butir item tes tersebut diubah menjadi nilai dengan cara mengkonsultasikan ke dalam tabel norma tes 1000 meter TKJI usia 13-15 tahun sehingga akan terlihat dari daya tahan kardiorespirasi vascular atlet. Adapun tabel nilai dan tabel norma tes kebugaran jasmani Indonesia (TKJI) usia 13-15 tahun adalah sebagai berikut.

\begin{tabular}{|c|c|c|}
\hline Lari 1000 meter & Nilai & Kategori \\
\hline sd 3'53" & 5 & Baik Sekali \\
\hline $3^{\prime} 05^{\prime \prime}-3^{\prime} 53^{\prime \prime}$ & 4 & Baik \\
\hline $3^{\prime} 54^{\prime \prime}-4^{\prime} 46^{\prime \prime}$ & 3 & Sedang \\
\hline $4^{\prime} 47^{\prime \prime}-6^{\prime} 04^{\prime \prime}$ & 2 & Kurang \\
\hline$\geq 6$ '05" & 1 & Kurang Baik \\
\hline
\end{tabular}

Tabel 3.8 Lari jarak sedang 1000 meter (Sumber : I Made Sriundy Mahardika, 2010:99)

Teknik analisis data dalam penelitian ini adalah menggunakan statistik deskriptif. Statistik deskriptif adalah statistik yang digunakan untuk menganalisis data dengan cara mendeskriptifkan atau menggambarkan data yang telah terkumpul. Jadi dalam penelitian ini peneliti menggunakan jenis analisis statistik deskriptif yang bertujuan untuk mendeskripsikan atau 
menggambarkan suatu data yang sudah terkumpul.

\section{HASIL DAN PEMBAHASAN}

\begin{tabular}{|l|l|l|l|}
\hline 12 & ANG & 4.10 menit & Sedang \\
\hline 13 & HRA & 4.11 menit & Sedang \\
\hline 14 & BGT & 4.09 menit & Sedang \\
\hline \multicolumn{2}{|c|}{ Rata-rata } & $\mathbf{3 , 6 8}$ menit & \\
\hline
\end{tabular}

Tujuan dari penelitian untuk mengetahui daya tahan atlet putri yang mengikuti kejuaraan piala gubernur KU C usia 13-15 tahun. Tes daya tahan ini diukur menggunakan lari 1000 meter. Hasil data yang diperoleh akan dimasukkan ke dalam nilai norma Lari $1000 \mathrm{~m}$ kebugaran jasmanai yang kemudian dijadikan patokan untuk mengetahui daya usia 13-15 tahun.

Deskripsikan hasil penelitian tes lari 1000 meter tersebut diuraikan sebagai berikut.

Tabel 4.1 Hasil Lari 1000 meter

\begin{tabular}{|c|l|c|c|}
\hline NO & NAMA & NILAI & NORMA \\
\hline 1 & RRT & 3.20 menit & Baik \\
\hline 2 & FNN & 3.54 menit & Sedang \\
\hline 3 & JSC & 3.43 menit & Baik \\
\hline 4 & STA & 3.34 menit & Baik \\
\hline 5 & AMZ & 3.67 menit & Sedang \\
\hline 6 & MSY & 3.50 menit & Sedang \\
\hline 7 & FLS & 3.52 menit & Baik \\
\hline 8 & KNZ & 3.66 menit & Sedang \\
\hline 9 & ABL & 3.50 menit & Baik \\
\hline 10 & TAR & 4.12 menit & Sedang \\
\hline 11 & MDW & 3.74 menit & Sedang \\
\hline
\end{tabular}

Tabel 4.2 Lari 1000 meter

\begin{tabular}{|c|c|c|c|c|}
\hline Nilai & $\begin{array}{c}\text { Lari 1000 } \\
\text { meter }\end{array}$ & Kategori & $\begin{array}{c}\text { Freku } \\
\text { ensi }\end{array}$ & $\begin{array}{c}\text { Presen } \\
\text { tase }\end{array}$ \\
\hline 5 & sd 3'53" & $\begin{array}{c}\text { Baik } \\
\text { Sekali (BS) }\end{array}$ & 0 & $0 \%$ \\
\hline 4 & $\begin{array}{c}3^{\prime} 05^{\prime \prime}- \\
3^{\prime} 53^{\prime \prime}\end{array}$ & Baik (B) & 5 & $35 \%$ \\
\hline 3 & $\begin{array}{c}3^{\prime} 54^{\prime \prime}- \\
4^{\prime} 46^{\prime \prime}\end{array}$ & Sedang (S) & 9 & $65 \%$ \\
\hline 2 & $\begin{array}{c}4^{\prime} 47^{\prime \prime}- \\
6^{\prime} 04^{\prime \prime}\end{array}$ & $\begin{array}{c}\text { Kurang } \\
\text { (K) }\end{array}$ & 0 & $0 \%$ \\
\hline 1 & $\geq 6^{\prime} 05^{\prime \prime}$ & $\begin{array}{c}\text { Kurang } \\
\text { Sekali } \\
\text { (KS) }\end{array}$ & 0 & $0 \%$ \\
\hline \multicolumn{2}{|c|}{ Jumlah } & $\mathbf{1 4}$ & $\mathbf{1 0 0 \%}$ \\
\hline
\end{tabular}

Berdasarkan tabel diatas hasil lari 1000 meter atlet putri finsswimming $\mathrm{Ku} \mathrm{C}$ dan $\mathrm{D}$ Dragon Wira yudha menghasilkan rata-rata 3,68 menit, dengan standar deviasi 0,3095406, nilai minimum 4,12 menit, nilai maximum 3,20 menit. Kategori Baik Sekali 0 siswa (0\%), Baik 5 siswa (35\%), Sedang 9 Siswa (65\%), Kurang 0 siswa (0\%), dan Kurang Sekali 0 siswa (0\%). 


\section{Gambar 4.1 Diagram Prosentase Lari 1000 meter}

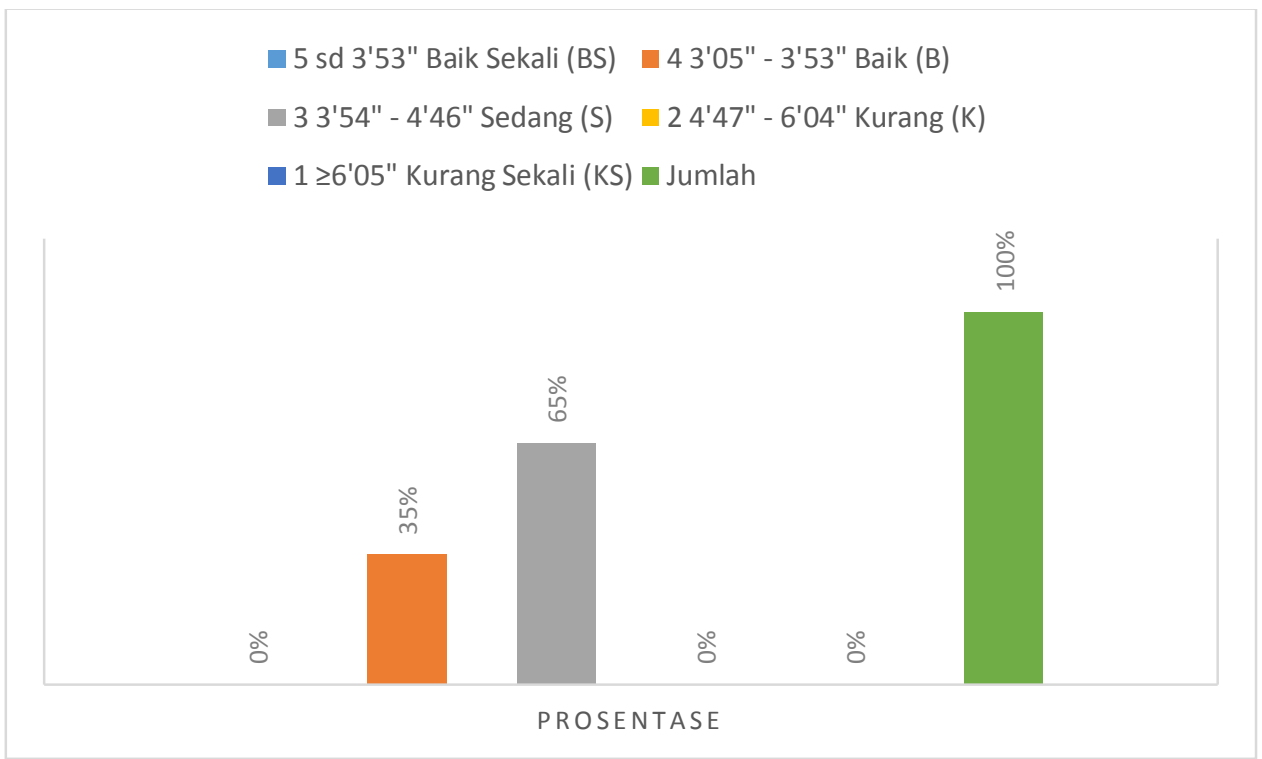

Berdasarkan diagram diatas atlet putri $\mathrm{Ku} \mathrm{C}$ dan $\mathrm{D}$ finsswimming Dragon wira yudha pada tes lari 1000 meter yang mendapatkan kategori Baik Sekali (0\%), Baik (35\%), Sedang (65\%), Kurang (0\%), dan Kurang Sekali (0\%).

Daya tahan (endurance) memiliki peranan yang sangat penting bagi atlet di cabang olahraga selam (finsswimming), jika seorang atlet ingin mendapatkan daya tahan tubuh yang baik harus melalui proses latihan. Pengukuran daya tahan kardiorespirasi vascular dapat dilakukan dengan cara mengukur (VO2max). VO2 max adalah jumlah maksimal oksigen yang dapat dikonsumsi selama aktivitas berlangsung sampai akhirnya terjadi kelelahan. Menurut Guyton, dalam Yan Syantica (2013:3) "VO2Max ini disebut tenaga aerobik maksimal yang menunjang seseorang dalam melakukan aktivitas jasmaninya". Untuk mengetahui baik buruknya VO2max dapat di lakukan pengukuran sebagai analisis suatu program latihan bagi atlet yang sedang berkembang, agar efektif sebaiknya latihan endurace meliputi durasi, frekuensi, dan itensitas latihan tertentu.

Berdasarkan hasil penelitian di atas maka pengukuran daya tahan kardiorespirasi vascular atlet putri KU C dan D finswimmng Piala Gubernur tahun 2019 menggunakan tes 1000 meter yaitu "SEDANG". hal ini terbukti pada kejuaraan finswimming piala Gubernur Jawa Timur tahun 2019 rata-rata atlet mendapatkan di nomor spinten 50 dan 100meter itu saja mendali perak dan perunggu, di nomor panjang 200 dan 400 meter tidak ada yang mendapatkan mendali sama sekali. Berdasarkan hasil di atas dapat disimpulkan bahwa daya tahan 
kardiorespirasi sangatlah penting dan berpengaruh dalam proses latihan, baik buruk peforma atlet juga bisa di lihat dari daya tahan kardiorespirasi pada saat kejuaraan sehingga berpenggaruh dapat hasil kejuaraan tersebut. Pernyataaan di atas sependapat dengan pernyataan Guyton, dalam Yan Syantica (2013:3) "VO2Max ini disebut tenaga aerobik maksimal yang menunjang seseorang dalam melakukan aktivitas jasmaninya". Untuk mengetahui baik buruknya VO2max dapat di lakukan pengukuran sebagai analisis suatu program latihan bagi atlet yang sedang berkembang, agar efektif sebaiknya latihan endurace meliputi durasi, frekuensi, dan itensitas latihan tertentu. Dengan demikian paparan diatas dapat disimpulkan VO2max memeliki peranan penting untuk menunjang atlet dalam berprestasi.

\section{SIMPULAN}

Berdasarkan hasil survei pada atlet putri finswimming $\mathrm{KU}$ C dan $\mathrm{D}$ menujukkan berada pada kategori Sedang(S) sebesar 35\% dan kategori baik (B) sebesar 65\% dengan rata-rata 36,8 yaitu masuk kategori sedang.

Untuk mendapatkan prestasi terbaik pada kejuaran finswimming piala Gubernur Jawa Timur KU C dan $\mathrm{D}$ putri harus memiliki kategori dengan rata-rata sangat baik.

\section{DAFTAR PUSTAKA}

Ahmadi, Pitdin. 2014. Skripsi Studi Analisis Kondisi Fisik (Vo2max) Atlet Futsal Sman 1 Putri Hijau Kabupaten Bengkulu Utara Tahun Ajaran 2013-2014. PJKR FKIP UNIB.

Arikunto, S. 2010. Prosedur penelitian suatu pendekatan pratik. Jakarta: PT Rineka Cipta

Djoko Pekik Irianto. (2004). Pedoman Praktis Berolahraga Untuk Kesegaran dan Kesehatan.Yogyakarta: Andi Offset.

I Made Sriundy Mahardika. (2010).Evaluasi Pengajaran: Unesa University Press.

Sharkey BJ. 2013. fitnes and health 2 nd ed. terjemahan Eri Desmarini Nasution. Jakarta grafindo persada. P.15, 72, 80-85, 99-100, 163-164, 236.

Putra, yan syantica. 2013. Perbedaan tes balke, tes cooper dan tes multistage terhadap daya tahan aerobik atlrt bola voli yuso sleman. Program studi pendidikan kepelatihan olahraga. Universitas negeri yogyakarta. 